\title{
A concepção behaviorista de Pavlov e Watson: implicações na educação profissional
}

\author{
Pavlov and Watson's behaviorist conception: implications for professional \\ education
}

\author{
ARAÚJO, Roberta Gomes de. Discente do curso de Mestrado em Educação Profissional e \\ Tecnológica \\ Instituto Federal de Educação Ciência e Tecnologia do Sertão Pernambucano- IF Sertão Campus Salgueiro. \\ Salgueiro - PE - Brasil. CEP: 56000-000. / Telefone: (89) 3522-2716/ E-mail: rga@ufpi.edu.br
}

\author{
JUNIOR, Edimilson Pereira e Silva. Discente do curso de Mestrado em Educação \\ Profissional e Tecnológica \\ Instituto Federal de Educação Ciência e Tecnologia do Sertão Pernambucano- IF Sertão Campus Salgueiro. \\ Salgueiro - PE - Brasil. CEP: 56000-000. / Telefone: (89) 3582 1933/ E-mail: edmilson.junior@ifpi.edu.br
}

\section{OLIVEIRA, Cristiane Ayala de. Doutora/Tecnóloga em Agroindústria}

Instituto Federal de Educação Ciência e Tecnologia do Sertão Pernambucano- IF Sertão Campus Salgueiro. Salgueiro - PE - Brasil. CEP: 56000-000. / Telefone: (87) 99664-3349 / E-mail: cristiane.ayala@ifsertaope.edu.br

\section{OLIVEIRA, Fábio Freire de. Doutor/ Docente do curso de Mestrado em Educação} Profissional e Tecnológica

Instituto Federal de Educação Ciência e Tecnologia do Sertão Pernambucano- IF Sertão Campus Salgueiro. Salgueiro - PE - Brasil. CEP: 56000-000. / Telefone: (87) 2101 2350/ E-mail: fabio.freire@ifsertao-pe.edu.br

\section{RESUMO}

O objetivo principal desse estudo foi analisar as principais contribuições do behaviorismo para a educação profissional. Os objetivos específicos são: compreender o behaviorismo de Pavlov e Watson, além de outras correntes behavioristas; conhecer as principais características da educação profissional; verificar relações da educação profissional à luz do behaviorismo. Percebe-se que Se forem utilizados processos de ensino-aprendizagem levando-se em grande parte subsídios das teorias de Watson e Pavlov, molda-se com certeza, educandos numa perspectiva de adestramento, acomodação e reprodução. 0 encaixe do ensino proposto atualmente é predisposição nas experiências internas e anteriores dos alunos, levando em consideração pontos cognitivos, sociais, culturais e afetivos, circunstâncias essas rompidas pelas teorias abordadas.

Palavras-chave: aprendizagem, condicionamento, estímulo-resposta.

\begin{abstract}
The main objective of this study was to analyze the main contributions of behaviorism to professional education. The specific objectives are: to understand the behaviorism of Pavlov and Watson, besides other behaviorist currents; know the main characteristics of professional education; to verify professional education relations in the light of behaviorism. It is perceived that If teaching-learning processes are used, and are largely based on Watson and Pavlov's theories, they are certainly shaped by a training, accommodation and reproduction perspective. The preschooling of the current teaching is predisposed in the students' internal and previous experiences, taking into account cognitive, social, cultural and affective points, which are broken by the theories addressed.
\end{abstract}

keywords: learning, conditioning, stimulus-response. 
ARAÚJO, R. G. de; JUNIOR, E. P. e S.; OLIVEIRA, C. A. de; OLIVEIRA, F. F. de;(2019). A concepção behaviorista de Pavlov e Watson: implicações na educação profissional

\section{Introdução}

O comportamentalismo surgiu no início do século XX, principalmente nos Estados Unidos, em oposição ao mentalismo que dominava a psicologia Européia na época. A ideia dessa tendência está vinculada a uma possível ciência do comportamento. "A principal ideia da teoria comportamentalista é o processo Estímulo-Resposta, e através deste princípio, os pensadores desenvolveram suas teorias" (SOARES, 2013, p.01). Baseiam-se nos comportamentos observáveis e mensuráveis dos sujeitos, e nas respostas que eles dão aos estímulos externos. 0 estudo do comportamentalismo acontece dentro da psicologia na linha teórica do Behaviorismo, que possui três tendências: Behaviorismo Cognitivo, Behaviorismo Metodológico e Behaviorismo Radical.

O criador do behaviorismo metodológico (também denominado como comportamentalismo), matéria de interesse desse estudo, é John B. Watson (1878-1958). Para ele o behaviorismo metodológico tem caráter empirista, onde rejeita os processos mentais como objeto de pesquisa. A introspecção não poderia ser aceita como prática científica, assim relata Sério (2005 citado por OSTERMANN; CAVALCANTI, 2011).

O Behaviorismo Metodológico apresenta também um caráter determinista. "Sendo uma teoria baseada em estímulo-resposta (E-R), nela há uma indicação de que o comportamento humano é previsível. Se um antecedente $X$ ocorre, o evento $Y$ ocorrerá como consequência" (PRIMO, 2009; OSTERMANN; CAVALCANTI, 2011, p.13).

Watson, assim como outros, foram influenciado pelo trabalho de Ivan Pavlov (1849-1936), no qual seus estudos com cachorros possibilitaram descobertas no âmbito da fisiologia e mais tarde, interpretadas no âmbito da psicologia. Para Pavlov, tudo que aprendemos é explicado através do modo em que os estímulos (ambientais e internos) produzem as respostas (SOARES, 2013).

Moreira (1999) enfatiza que essas teorias trouxeram um grande enfoque tecnológico para a instrução, que durante as décadas de sessenta e setenta, dominaram as atividades didáticas nas mais variadas matérias de ensino. A ação docente era pautada em apresentar estímulos na quantidade e momentos certos, com intuito de aumentar ou diminuir a frequência de certos comportamentos nos alunos.

Watson colocava que cabe ao professor promover o maior número de vezes possível a associação de uma resposta (desejada) a um estímulo para que o aprendiz adquira conhecimentos, isso explicado através do Princípio da Frequência. Já o Princípio da Recentidade coloca que o professor deverá proporcionar ao estudante o vínculo mais rápido possível entre a resposta que ele quer que o aluno aprenda e o estímulo a ela relacionado (OSTERMANN; CAVALCANTI, 2011).

Estas ideias não são recentes e estão associadas a uma pedagogia tecnicista que é muito criticada atualmente. A partir desta breve discussão nos foi suscitado o seguinte questionamento: como as principais características do behaviorismo se apresentam no processo de aprendizagem na educação profissional?

A abordagem desse trabalho permite identificar possíveis contribuições dessa teoria para a prática de ensino, e possibilita ao docente implementar em seu itinerário novas formas de ensinar, esclarecer pontos iniciais de aprendizagem. Permite ainda conhecer as dimensões do aprender em 
ARAÚJO, R. G. de; JUNIOR, E. P. e S.; OLIVEIRA, C. A. de; OLIVEIRA, F. F. de;(2019).

A concepção behaviorista de Pavlov e Watson: implicações na educação profissional

frente ao comportamento humano e ao resultado dos estímulos dados.

Esse estudo tem como objetivo principal analisar as principais contribuições do behaviorismo para a educação profissional. Os objetivos específicos são: compreender o behaviorismo de Pavlov e Watson, além de outras correntes behavioristas; conhecer as principais características da educação profissional; verificar relações da educação profissional à luz do behaviorismo.

\section{Comportamentalismo/Behaviorismo}

O estudo do comportamento acontece dentro da psicologia na linha teórica do comportamentalismo. Este estudo é chamado de Behaviorismo, possuindo três tendências: Behaviorismo Cognitivo, Behaviorismo Metodológico e Behaviorismo Radical.

No Behaviorismo Cognitivo se pressupõe que existe uma relação entre o mundo, como ambiente externo ao indivíduo, que desencadeia neste pensamentos e sentimentos que irão determinar seu comportamento no ambiente (KAHHALE, 2011). No Behaviorismo Metodológico há uma ênfase aos procedimentos de medida do comportamento em sua relação com o ambiente ficando conhecido como a Psicologia do S-R onde S operacionaliza o ambiente e R o comportamento (MATOS, 1997 citado por KAHHALE, 2011). O Behaviorismo Radical entende que o ambiente que se encontra o homem determina e constrói as características que são _particulares a cada um (KAHHALE, 2011).

O surgimento do comportamentalismo/Behaviorismo aconteceu nos Estados Unidos da América e muitos autores apresentam John Broadus Watson (1878-1958) como o seu fundador, pois o mesmo se dedicou a fundar uma nova escola de pensamento para a Psicologia. Schultz (2012) lembra que:

(...) não foi Watson quem deu origem a essas ideias básicas do movimento behaviorista; elas já vinham sendo desenvolvidas há algum tempo, tanto na psicologia como na biologia. Como qualquer outro fundador, Watson organizou e promoveu as ideias e as questões já aceitáveis para o Zeitgeist intelectual. Assim, são estes alguns dos principais conceitos reunidos pro Watson para formar seu sistema de psicologia behaviorista: a tradição filosófica objetivista e mecanicista; a psicologia animal; e a psicologia funcional.(SCHULTZ, 2012, p. 230).

Outra influência importante para Watson foi a de Ivan Petrovitch Pavlov (1849-1936) , pois o seu método auxiliou nos estudos de controle e modificação do comportamento por Watson.

Pavlov trabalhou com três questões centrais: a função dos nervos cardíacos, as glândulas digestivas primárias e o estudo dos reflexos condicionados que the rendeu lugar de muito destaque na História da Psicologia.

O reflexo condicionado ocorreu de uma descoberta acidental: em um trabalho com as glândulas digestivas dos cães, Pavlov percebeu que os cachorros salivavam também antes de receberam a comida, isto acontecia com o som dos passos dos homens que geralmente os alimentavam. Esta reação de salivação se condicionou ao estímulo que antes era associado ao 
ARAÚJO, R. G. de; JUNIOR, E. P. e S.; OLIVEIRA, C. A. de; OLIVEIRA, F. F. de;(2019). A concepção behaviorista de Pavlov e Watson: implicações na educação profissional

recebimento da comida. As experiências iniciais de Pavlov com os cães foram simples conforme explica Schultz e Schultz (2012):

Ele segurava um pedaço de pão e o mostrava ao cachorro antes de dá-lo para comer. Com o tempo, o cachorro começava a salivar assim que via o pão. A resposta de salivação do cachorro quando a comida era colocada na sua boca era uma reação natural de reflexo do sistema digestivo e não envolvia a aprendizagem. Pavlov denominou essa reação de reflexo inato ou não-condicionado. (SCHULTZ, 2012, p. 245).

A este acontecimento Pavlov chamou de reflexo psíquico. Já a salivação que ocorria pela visão da comida devia ser aprendida, logo ele denominou este acontecimento de reflexo condicionado_ou dependente que ocorria na formação de uma associação ou ligação entre o estímulo e a resposta (SCHULTZ e SCHULTZ, 2012).

0 experimento de condicionamento ocorria da seguinte maneira: primeiro se apresentava o estímulo condicionado e imediatamente o incondicionado. Schultz e Schultz (2012) citam o exemplo em que o estimulo condicionado é a luz, e o incondiconado a comida. 0 pesquisador acendia a luz e imediatamente apresentava a comida. Após várias repetições do acendimento da luz e entrega imediata da comida, os cães passavam a salivar com a simples visão da luz. Criando, assim, uma associação da luz -e a comida, isto permitia que o animal ficasse condicionado a responder mediante a apresentação do estímulo. Pavlov percebeu que a aprendizagem ou condicionamento só ocorreria se este processo ocorresse um número de vezes suficiente. Assim, o reforço é necessário para que a aprendizagem ocorra.

\section{Behaviorismo Metodológico de Watson}

A cristalização das ideias já emergentes do behaviorismo ocorreram por meio dos esforços de Watson que se propôs a construir esta escola de pensamento. Watson no início da carreira se propôs a estudar sobre os efeitos do álcool e dos filmes de educação sexual nos adolescentes, os efeitos positivos e negativos caso houvesse. A instituição onde o mesmo trabalhava não aceitou muito bem a ideia deste estudo e solicitou que o Watson parasse. Em 1913 ele lançou um artigo na Revista Psychologic al Review fato este que lançou oficialmente o Behaviorismo. Após isto Watson publicou o livro Behavior: an introduction to comparative psychology (1914) que versava sobre as vantagens da utilização do uso de animais nas pesquisas psicológicas. Em 1928 ele discorreu sobre as práticas da Educação Infantil no livro Psychological care of the infantand child onde ele propôs um ensino não permissivo e segundo ele os pais nunca deveriam:

(...) abraçar e beijar, jamais as deixem sentar no colo. Quando estritamente necessário, beijem mas apenas uma vez na testa ao lhes dar boa noite. Pela manhã, cumprimentem-nas com um aperto de mão. Afaguem-lhes a cabeça, caso realizem mito bem uma tarefa extremamente difícil. (...) vocês perceberão como é fácil serem perfeitamente objetivos com os filhos e ao mesmo tempo gentis. Vocês se sentirão totalmente envergonhados da forma sentimental e insípida de como os estavam tratando. (WATSON, 1928, p.81-82; SCHULTZ, 2012, p.262). 
ARAÚJO, R. G. de; JUNIOR, E. P. e S.; OLIVEIRA, C. A. de; OLIVEIRA, F. F. de;(2019). A concepção behaviorista de Pavlov e Watson: implicações na educação profissional

Para Watson a psicologia devia se limitar ao estudo objetivo do comportamento e alguns métodos deviam ser adotados nos laboratórios dos behavioristas como por exemplo: a observação com e sem instrumentos, métodos de teste, de relato verbal e do reflexo condicionado.

A observação foi a base fundamental para os outros métodos; métodos de teste, ele sugeriu tratar os resultados dos testes como amostragens do comportamento e não como indicadores de qualidades mentais; no relato verbal ele considerou as reações orais significativas para o behaviorismo, bem como qualquer resposta motora e_considerou que falar é um comportamento tão objetivo quanto jogar beisebol; o reflexo condicionado foi amplamente divulgado por Watson, nele a resposta tornava-se condicionada quando associada ou conectada a um estímulo diferente, este método permitia que os psicólogos conduzissem as investigações sobre o comportamento humano em laboratórios.

O behaviorismo de Watson foi uma tentativa de construir uma ciência livre de noções e métodos subjetivos, uma ciência tão objetiva quanto a física (SCHULTZ e SCHULTZ, 2012). Para Watson o instinto, a emoção e o pensamento eram temas principais.

No livro Behavior: na introduction to comparative psychology (1914) ele descreveu 11 instintos, mas depois eliminou o conceito de instinto alegando que os comportamentos que antes ele entendia serem intuitivos eram na verdade respostas condicionadas socialmente. Adotando a visão da aprendizagem, ele negou qualquer tipo de talento, temperamento ou capacidade herdado. Logo ele se tornou um ambientalista, pois acreditava que não havia nada herdado e que os comportamentos estavam relacionados com os estímulos recebidos na primeira infância. Para ele uma criança poderia ser treinada para ser o que quiserem, mediante do incentivo e reforço do comportamento adequado.

As emoções não passavam de simples respostas fisiológicas a estímulos específicos, provocando mudanças físicas internas com um padrão particular. Dessa forma a emoção é expressa por meio de manifestações físicas como por exemplo o aumento dos batimentos cardíacos. Watson inspirou uma pesquisa muito importante sobre a terapia do comportamento (aplicação dos princípios de aprendizagem para alterar o comportamento desajustado) (SCHULTZ e SCHULTZ, 2012).

Esta pesquisa foi desenvolvida com uma criança de três anos que possuía medo de coelhos. No momento em que Peter comia era trazido para perto dele um coelho branco e cada vez o aproximavam até que em um dado momento Peter o tocou. Não ocorrendo assim a resposta de medo que sempre era produzida nesta circunstância.

Para Watson, o comportamento compunha-se inteiramente de impulsos fisiológicos. Devido à influência de Pavlov, focalizou seu estudo muito mais nos estímulos do que nas consequências e, assim, encarou a aprendizagem na forma do condicionamento clássico: o estímulo condicionado, depois de ser emparelhado um número suficiente de vezes com o estímulo incondicionado, passa a eliciar a mesma resposta e pode substituí-lo. OSTERMANN; CAVALCANTI, 2011, p.18).

Quanto aos processos do pensamento, Watson acreditava que não eram passíveis de observação e experimentação, pois ocorria na ausência de movimentos musculares. Para ele este 
ARAÚJO, R. G. de; JUNIOR, E. P. e S.; OLIVEIRA, C. A. de; OLIVEIRA, F. F. de;(2019).

A concepção behaviorista de Pavlov e Watson: implicações na educação profissional

processo do pensamento que faz parte do comportamento implícito está concentrado no músculo da língua e da laringe, expressando-o por meio de gestos como o movimento dos ombros e franzir da testa. Mas com o tempo vamos deixando de externalizar estes comportamentos implícitos do pensamento, pois vamos sendo reprimidos por pais e professores a pensar com hábitos musculares invisíveis. As ideias de Watson geraram grande entusiasmo a época no efeito da criação e do ambiente infantil:

As experiências de Watson acerca do reflexo condicionado, tais como o estudo com Albert, convenceram-no de que os distúrbios emocionais do adulto são provocados pelas respostas condicionadas estabelecidas na infância e na adolescência. $E$, se o desequilíbrio do adulto é resultante do condicionamento infantil adequado evitaria o surgimento de adultos desequilibrados. Watson acreditava que esse tipo de controle prático sobre o comportamento infantil (e, consequentemente, sobre o comportamento adulto posterior) não era apenas possível, como também absolutamente necessário. Ele desenvolveu um plano para a melhoria da sociedade, um programa de ética experimental, baseado nos princípios do behaviorismo. (SCHULTZ e SCHULTZ, 2012, p. 273).

Watson, em relação ao aprendizado colocava que cabe ao professor promover o maior número de vezes possível a associação de uma resposta (desejada) a um estímulo para que o aprendiz adquira conhecimentos, isso explicado através do Princípio da Frequência. Já o Princípio da Recentidade coloca que o professor deverá proporcionar ao estudante o vínculo mais rápido possível entre a resposta que ele quer que o aluno aprenda e o estímulo a ela relacionado (OSTERMANN; CAVALCANTI, 2011).

Pensamentos esses que nos remete a comparar o trabalho de Watson a métodos de ensino tecnicista e reprodutor do modo tradicional, com condicionamento a repetição e fixação de conteúdos impostos, sem aplicação do estimulo e engajamento nos métodos ativos de ensino, diferente das novas propostas que galgam a educação atual.

\section{Behaviorismo Radical}

No ano de 1945, Burrhus Skinner publicou o livro "The Operational Analysis of Psychological Terms", tentando assim de responder às correntes internalistas do comportamentalismo, além disso era influenciado pelo behaviorismo filosófico. Com a publicação do referido livro deu-se gênesis a corrente comportamentalista denominada de Behavorismo Radical, que foi desenvolvido como uma proposta de reflexão sobre o comportamento humano, e não experimental, opondo-se à concepção de Watson (VESCE, 2016).

Burrhus Frederic Skinner comumente conhecido como B. F. Skinner, foi um psicólogo behaviorista, inventor e filósofo americano, que viveu de 1904 a 1990. Sua percurso profissional foi direcionado para a psicologia apenas na universidade de Harvard, onde iniciou seu primeiro contato com a teoria behaviorista. Esse estudioso propôs atividades que envolviam experiências práticas com animais (pombos e ratos), baseando-se nessas observações para produção de seus livros (ARAÚJO, 2019). 
ARAÚJO, R. G. de; JUNIOR, E. P. e S.; OLIVEIRA, C. A. de; OLIVEIRA, F. F. de;(2019). A concepção behaviorista de Pavlov e Watson: implicações na educação profissional

Skinner elaborou o conceito de Condicionamento Operante, "que diferenciava do Condicionamento Clássico de Watson, transferiu-se a ênfase do estímulo antecedente (como no caso do condicionamento clássico) para o estímulo consequente como recurso para se garantir a manutenção ou extinção de certo comportamento” (ALMEIDA et al., 2013, p.83).

Skinner foi radical contra causas internas, ou seja, mentais, para explicar a conduta humana e negou também a realidade e a atuação dos elementos cognitivos, opondo-se à concepção de Watson. Ele acredita que o indivíduo é um ser único, homogêneo, não um todo constituído de corpo e mente (SANTANA, 2016).

Almeida et al. (2013, p. 83) relata que para Skinner, "os trabalhos internos da mente e de corpo estavam inacessíveis à observação direta e, para se compreender o comportamento, bastava entender o ambiente em que uma resposta ocorria a própria resposta e a consequência da resposta". Sobre o behaviorismo desta geração Coelho e Dutra afirmam que:

Os behavioristas radicais postulados por Skinner entendem, portanto, todos os eventos naturais, sujeitos a acessos, incluindo acontecimentos públicos e privados; e excluem os fictícios - que não podem ser acessados. A mente e os processos, como causas mentais do comportamento, são considerados fictícios e, por conseguinte, constituem "termos" que devem ser evitados. Os behavioristas radicais assumem, dessa forma, que as causas do comportamento encontram-se na hereditariedade e no ambiente passado e presente. (COELHO; DUTRA, 2018, p.56).

O próprio Skinner relata,

(...) o behaviorismo radical restabelece um certo tipo de equilíbrio. Não insiste na verdade por consenso e pode, por isso, considerar os acontecimentos privados dentro da pele. Não considera tais acontecimentos inobserváveis e não os descarta como subjetivos. Simplesmente questiona a natureza do objeto observado e a fidedignidade das observações (SKINNER, 1974, p. 19; COELHO; DUTRA, 2018, p.56).

Assim, os seguidores do behaviorismo radical acreditam que para explicar os diferentes universos presentes no comportamento dos seres humanos, há necessidade de embasamento em evidências refutáveis e não somente em especulações abstratas (ARAÚJO, 2019, p.2).

O behaviorismo radical busca as causas do comportamento, a explicação do comportamento, nas histórias genética e ambiental de uma pessoa. Apresenta-se, assim, como uma proposta bastante peculiar para a psicologia, pois recusa as concepções tradicionais que marcaram o início da psicologia e são até hoje bastante difundidas. Essa corrente não fundamenta-se em razões metodológicas, para evitar assim o mentalismo, e usa o recurso ambiente para busca das causas do comportamento (SERIO, 2005).

Sério (2005), também descreve que as razões do behaviorismo radical estão relacionadas à concepção de comportamento proposta: onde comportamento (qualquer que seja) é visto como interação entre o organismo e o ambiente; o comportamento atual é uma interação momentânea e ao mesmo tempo resultado de interações anteriores. Nessa perspectiva entende-se que o termo ambiente está compreendido de uma forma amplificada, não reduzindo-se àquele apresentado apenas no momento quando uma resposta acontece, é necessário levar em consideração 
ARAÚJO, R. G. de; JUNIOR, E. P. e S.; OLIVEIRA, C. A. de; OLIVEIRA, F. F. de;(2019).

A concepção behaviorista de Pavlov e Watson: implicações na educação profissional

experiências vividas anteriormente em um determinado ambiente.

\section{Behaviorismo Cognitivo}

O Cognitivismo apesar de não terem sidos criados fora do campo da psicologia teve grande influência para seu crescimento do avanço científico para além desse segmento. "Estes avanços foram basicamente seis: o advento da computação, a Teoria da Informação, a Cibernética, as novas teorias neurológicas, as novas descrições de síndromes neuropsicológicas e a teoria linguística de Noam Chomsky" (CASTAÑON, 2006, p. 171).

A interpretação tradicionalista das condições de surgimento da Ciência Cognitiva e do Cognitivismo, concorda plenamente em duas teses:

A primeira, é que a recusa sistemática da Psicologia de antes dos anos sessenta em utilizar o método científico para investigar os fenômenos legitimamente psicológicos propiciou naturalmente essa "invasão", e não somente os avanços científicos considerados. A segunda, é que o surgimento do Racionalismo Crítico é tão fundamental para se compreender o surgimento da Psicologia Cognitiva quanto estes avanços científicos. (CASTAÑON, 2006, p.171)

Sem contestações a mais importante influência da revolução cognitiva foi o advento do computador. "Desde o surgimento da teoria matemática da Máquina de Turing até o desenvolvimento dos computadores de processamento paralelo, a chamada metáfora computacional tem sido a mais preciosa fonte de ideias para a Psicologia Cognitiva" (CASTAÑON, 2006, p.177)

Pode-se interpretar que a psicologia cognitiva segmenta áreas específicas, como a memória, percepção, atenção, aprendizagem, tomada de decisão, a aquisição da linguagem, resolução de problemas e esquecimento. Essa área de conhecimento tenta compreender o processo de aprendizagem de coisas novas, lembram-se de informações, pensam e chegam a decisões (AZEVEDO, 2016).

O cognitivismo propõe analisar a mente, o ato de conhecer como o homem desenvolve seu conhecimento acerca do mundo, analisando os aspectos que intervém no processo estímulo/resposta. A abordagem cognitivista, "apesar de ter surgido quase no mesmo período que o behaviorismo, teve grande efervescência nos anos de 1990, resgatando estudos teóricos da Psicologia Cognitiva como aqueles desenvolvidos por Piaget e Vigotsky” (SANTOS, 2019, p. 101).

\section{Educação Profissional e Tecnológica}

Quando se fala em educação profissional ainda há muitas dúvidas sobre como deve ser desenvolvida esta modalidade de ensino. Há uma ideia equivocada que a educação profissional deve única e exclusivamente formar mão-de-obra qualificada para o trabalho. Estudos como o de Barato (2008), Moura, Filho e Silva (2015), nos ajudará a ter uma melhor compreensão sobre o ideal e o real na Educação Profissional (EP) 
ARAÚJO, R. G. de; JUNIOR, E. P. e S.; OLIVEIRA, C. A. de; OLIVEIRA, F. F. de;(2019) A concepção behaviorista de Pavlov e Watson: implicações na educação profissional

A EP foi por muito tempo um instrumento que servia aos interesses do capital, e ao mesmo tempo_tentava "resolver" o problema da classe trabalhadora pobre que necessitava de um ofício para thes gerar uma renda, e inocentemente servia ao capital, pois a partir dessa moeda de troca se tinha mão-de-obra barata, rápida e certa. Para Frigotto (2001):

[...] a educação geral e, particularmente, a educação profissional vinculada a uma perspectiva de adestramento, acomodação, mesmo que se utilizem noções como as de educação polivalente e abstrata. Trata-se de conformar um cidadão mínimo, que pensa minimamente e que reaja minimamente. Trata-se de uma formação numa ótica individualista, fragmentária - que sequer habilite o cidadão e lhe dê direito a um emprego, a uma profissão, tornando-o apenas um mero "empregável" disponível ao mercado de trabalho sob os desígnios do capital em sua nova configuração. (FRIGOTTO, 2001, p.12)

$\mathrm{Na}$ realidade educacional brasileira, a relação "educação e trabalho" alimentou-se de "questões ventiladas por desigualdades sociais, cabendo ao ensino profissionalizante uma função assistencial, garantindo empregos não tão bem remunerados aos que dificilmente poderiam pleitear carreiras mais sólidas no ensino regular". (PAULA e MACHADO, 2017, p.13)

Esta formação propiciava apenas meios para que a classe trabalhadora aprendesse a fazer manuseios básicos de seus instrumentos de trabalho, não se formava para a transformação da natureza, da sua realidade. Não se formava para uma reflexão sobre a atividade que estava sendo desenvolvida.

Cunha (2000) discorre sobre o "nascimento" das séries metódicas de ofício que surgiram com o Sistema $\mathrm{S}$ respondendo aos anseios e necessidades do setor produtivo possibilitando o disciplinamento das condições de trabalho. 0 mesmo também apresenta a metodologia de ensino utilizada na educação profissional, dividia-se em quatro fases: 1 . Individualidade do aluno, 2. Estudo do assunto, 3. Comprovação do conhecimento e 4. Aplicação, generalização ou transferência do conhecimento. Cunha descreve que no processo de ensino-aprendizagem:

Cada aluno deve ter a possibilidade de iniciar aprendizagem e termina-la quando estiver preparado para isso, sem levar em conta o nível de adiantamento de seus colegas; o docente deve poder atender cada aluno individualmente e cuidar, ao mesmo tempo, do grupo todo, oferecendolhes estimulação e despertando o interesse; cada aluno deveria receber assistência que necessitar, sem interferir com o progresso dos demais colegas; cada aluno deveria progredir de acordo com suas aptidões, seus esforços e interesses, sem prejudicar ou ser prejudicado pelo progresso de seus companheiros de grupo. (CUNHA, 2000, p.72).

Esta metodologia de ensino condicionava o aprendiz a limitar-se apenas a reprodução dos conhecimentos que já foram elaborados, assim a institucionalização da educação profissional no Brasil foi baseada numa pedagogia tecnicista que objetivava a assimilação da realidade de trabalho dada por meio de métodos de ensino programados que priorizavam o treinamento e disciplinamento por meio do controle das situações de aprendizagem, gerando assim a robotização do ser humano (ARAÚJO e RODRIGUES, 2010).

Esta ideia de reduzir as atividades produtivas a execuções sem inteligência exigiria além do 
ARAÚJO, R. G. de; JUNIOR, E. P. e S.; OLIVEIRA, C. A. de; OLIVEIRA, F. F. de;(2019) A concepção behaviorista de Pavlov e Watson: implicações na educação profissional

empobrecimento do conteúdo do trabalho, uma mão-de-obra sem capacidades intelectuais (Barato, 2008). 0 mesmo traz como exemplo o texto ficcional Admirável Mundo Novo de Aldous Huxley. Neste romance os trabalhadores são programados desde a concepção in vitro:

No romance de Huxley, essa mão de obra ganha concretude naquelas centenas de gêmeos delta encarregadas do serviço pesado do hospital onde falece a mãe do Selvagem, personagem central da trama. Na cena memorável em que o herói tenta dissuadir os trabalhadores deltas a não tomarem sua dose diária de soma, a droga da felicidade, percebe-se que aqueles seres são incapazes de qualquer pensamento que ultrapasse as necessidades de manejo de materiais de limpeza e os desejos de drogar-se. As limitações desses personagens de ficção acontecem porque os deltas foram biologicamente programados para um fazer desprovido de significado. Sem tal programação, haveria seres humanos comuns, sempre capazes de atribuir sentido ao trabalho mesmo que esvaziado de conteúdo. (BARATO, 2008, p.72).

Limitar o ensino na EP a mera repetição nos faz alimentar a distinção arcaica e ultrapassada de quem, utiliza a ciência e (as pessoas que pertencem a classe dominante, a elite que tem acesso ao conhecimento científico) quem executa o trabalho manual (a classe pobre, operária) mediante o ensino de atividades específicas de forma isolada (BARATO, 2008).

\section{Material e métodos}

Do ponto de vista dos procedimentos, essa pesquisa é de natureza bibliográfica, onde sua principal vantagem é possibilitar ao investigador a cobertura de uma gama de acontecimentos muito mais ampla do que aquela que poderia pesquisar diretamente (GIL, 2006). A técnica bibliográfica visa a encontrar as fontes primárias e secundárias e os materiais científicos e tecnológicos necessários para a realização do trabalho científico ou técnico-científico. (OLIVEIRA, 2002).

Essa pesquisa se caracteriza como sendo exploratória, pois possibilita o desenvolvimento de um maior conhecimento sobre o tema, sendo apropriada para os primeiros estágios da investigação quando a familiaridade, o conhecimento e a compreensão do fenômeno por parte do pesquisador são, geralmente, insuficientes ou inexistentes (MATTAR, 2005).

Esse estudo também é de cunho qualitativo, onde a interpretação dos fenômenos e a atribuição de significados são básicas no processo de pesquisa qualitativa. Não requer o uso de métodos e técnicas estatísticas (GIL, 2006).

Para o levantamento da bibliografia foram realizadas pesquisas de texto no banco de dados dos Portal de Periódicos da CAPES e SCIELO, além da ferramenta Google Acadêmico. O recorte temporal não foi utilizado nessa pesquisa no intuito de se coletar o maior número de matérias publicados, visto que publicações nessa área é de pouco volume, principalmente quando se restringe buscas em um pouco espaço de tempo. Utilizou-se palavras-chave: teorias de aprendizagem; Behaviorismo; behaviorismo de Watson; teorias de Skinner; behaviorismo cognitivo; Educação Profissional e Tecnológica. 0 banco de referências para construção desse trabalho foi composto por artigos de revistas e periódicos, textos de sites relacionados, livros impressos, 
ARAÚJO, R. G. de; JUNIOR, E. P. e S.; OLIVEIRA, C. A. de; OLIVEIRA, F. F. de;(2019). A concepção behaviorista de Pavlov e Watson: implicações na educação profissional

trabalhos acadêmicos como teses e dissertações, além de estudos publicados em eventos científicos.

Procurou-se selecionar materiais que destacassem as teorias comportamentais: Behaviorismo Cognitivo, Behaviorismo Metodológico e Behaviorismo Radical. Além disso foram selecionados estudos dos principais autores das tendências behavioristas. A escolha de bibiografias importantes se deram também em torno dos principais estudiosos da educação profisionais tecnológica, como Frigotto, Barato e Cunha.

As informações coletadas e descrita nesse estudo culminam desenvolve uma discussão sobre o behaviorismo e seus impactos na educação profissional, tendo como objetivo compreender o behaviorismo e as principais características da educação profissional, verificando possíveis aspectos e relações da educação profissional à luz do behaviorismo.

\section{Resultados e discussão}

O estudo das teorias de aprendizagem é um recurso importante e indispensável para que o docente possa se definir, e a partir desta definição organizar a sua prática docente dentro de uma escolha que se apresente como a mais adequada para o seu campo, tempo, local e necessidade de atuação. Há três principais enfoques teóricos relacionados a aprendizagem e ensino apresentados por Moreira (1999): comportamentalismo, cognitivismo e humanismo.

No Behaviorismo, Pavlov acreditava que a aprendizagem só acontecia se houvesse o processo de repetição um número de vezes suficientes, assim o reforço era necessário. Este reforço nos remete a ideia equivocada que ainda se tem da EP, com foco apenas na formação de mão-de-obra para o mercado de trabalho. Para Frigotto (2001), este tipo de EP está vinculada a uma formação de cidadão mínimo, que pensa minimamente e que reage ao mesmo modo a partir de estímulos.

Não é exagerado afirmar que a Educação Profissional e Tecnológica (EPT) acompanha o homem desde os tempos mais remotos, quando os saberes e técnicas eram transferidos aos profissionais pela observação, pela manuseio prático e pela repetição. Aprendia-se por ensaios e erros, repetindo-se os saberes acumulados (VIEIRA; SOUZA JUNIOR, 2016). Então, num dado momento a EPT aproximou-se das concepções behavioristas, mas não galgou sempre em direção a elas.

Watson entendia que o ensino deveria ser objetivo, livre de métodos subjetivos, entendendo que as respostas eram condicionadas socialmente. Esta objetividade traça uma linha para que seja inserido todos os alunos, negando os talentos, temperamentos ou qualquer coisa que seja herdado. Watson acreditava que a partir de estímulos recebidos na primeira infância a criança poderia ser treinada para o que quisessem mediante incentivo e reforço adequado. No contexto da EP a utilização desta abordagem de aprendizagem só corrobora para a perpetuação de que a EP deve estar vinculada a uma perspectiva de adestramento para o ensino de um ofício, sem reflexão na atividade que está sendo desenvolvida.

Nesse argumento de suas abordagens, Watson menospreza a capacidade de aprendizado e mudança de comportamento na adolescência e vida adulta, impondo que apenas na infância, condicionando estímulos repetitivos, o indivíduo na vida adulta vai ser algo completo. Ora, então a 
ARAÚJO, R. G. de; JUNIOR, E. P. e S.; OLIVEIRA, C. A. de; OLIVEIRA, F. F. de;(2019). A concepção behaviorista de Pavlov e Watson: implicações na educação profissional

educação profissional, aplicada na adolescência e na vida adulta, não servem de nada segundo essa ótica de modelo de aprendizagem?

Esse é um questionamento que aproxima a conspiração dessa abordagem numa vertente apenas fisiológica, de modo reprodutor do que the é imposto, evadindo-se das contribuições de vivência, experiências internas e empíricas, elementos esse muito influentes no novo modelo de educação profissional, que há tempos vem tentando fragmentar o tecnicismo educacional.

O condicionamento operante reverenciado por Watson reforça a pedagogia tecnicista, que estimula o treinamento e disciplinamento por meio do controle das situações de aprendizagem, não permitindo que os sujeitos possam refletir sobre o processo educativo que vem sendo desenvolvido a partir da concepção de formação para o trabalho e para vida.

É preciso promover o desenvolvimento de amplas capacidades humanas, intelectuais e práticas, colocando o trabalho como princípio educativo somente quando compreendido na perspectiva de revolução social (ARAÚJO e FRIGOTTO, 2015).

Paula e Machado (2017) citam que antes de qualquer questão, deve-se considerar que a educação é um fenômeno sociocultural, que, ao longo dos tempos, vem acompanhando as transformações sociais, políticas e culturais de um povo. Assim, é preciso entender que educar é uma prática social e, como tal, fundamenta-se em questões históricas, políticas, jurídicas e ideológicas. Esse pensamento afirma que a vai além de mera adaptação anatômica ou fisiológica, se distribuí nos processos mentais de um ser humano social, emocional, cultural e político.

Esses mesmos estudiosos completam afirmando que a "educação, em sentido vulgar, é o ato por meio do qual se dá a alguém todos os cuidados necessários ao pleno desenvolvimento de sua personalidade. Ser educado é, pois, ser elevado, aperfeiçoado, instruído" (PAULA e MACHADO, 2017, p.14).

Quando relaciona-se alguns estudiosos com as teorias de aprendizagem e comportamento apresentadas nesse texto, nota-se que vão de desencontro no que concerne a seus princípios, não servindo essas como subsídios para o modelo de educação, que há muito tempo, se pretende alcançar.

Em contrapartida, quando se observa as contribuições de Skinner junto ao modelo de EPT atual, percebe-se que ocorrem uma aproximação positiva, logo, esse estudioso, com o behaviorismo radical, assumem, "que as causas do comportamento encontram-se na hereditariedade e no ambiente passado e presente" (COELHO; DUTRA, 2018, p.56). Ou seja, essa vertente leva em consideração aspectos ambientais e experiências anteriores do indivíduo para produzir determinadas respostas ao estimulo (aprendizado). Nesse viés entende-se o indivíduo aprendiz como sendo um ser social, multiplicados de experiências, e que toma situações iniciais para produção de seu conhecimento e existência própria, produz resultados de acordo com as situações que o ambiente the proporciona e flexibiliza.

Nessa perspectiva, nota-se através dos estudos que a EPT pretende favorecer o processo de ensino-aprendizado por meio da colaboração da experiências iniciais do aluno, sendo ele um ser social, que responde a estímulos que o ambiente educacional the proporcione, não sendo apenas um ser reprodutor, fisiológico, que the aprende por repetição, por reforço ou por punição. Então, esse 
ARAÚJO, R. G. de; JUNIOR, E. P. e S.; OLIVEIRA, C. A. de; OLIVEIRA, F. F. de;(2019).

A concepção behaviorista de Pavlov e Watson: implicações na educação profissional

direcionamento pode-se afirmar que deve-se em alguns pontos afastar-se de pressupostos do behaviorismo e aproximar-se de outros quando se trata de uma nova abordagem de ensino tecnológico.

\section{Conclusões}

O corpo deste trabalho mostrou que Pavlov estudou os elementos que podiam explicar a aprendizagem por meio do condicionamento, tomando os princípios de aplicação de estímulos e reforço como aliados. Entendeu que para ocorrer um aprendizagem é necessário e suficientes que dois estímulos sejam associados. Então, os estudos pavlovianos esclarecem por que os estudantes podem gostar ou não de uma determinada disciplina, escola ou professor.

O behaviorismo de Watson veio estabelecer uma ruptura com a introspecção, afirmando que a matéria-prima da psicologia deveria ser o comportamento. Nesse sentido os trabalhos desse estudioso teve grande influência na prática escolar e familiar, pois elucidava que as condições ambientais tem grande influência para mudança nos padrões comportamentais, que controlados, esses têm grande influência no processo de ensino-aprendizagem e conduta humana.

Entende-se aqui que a abordagem behaviorista, embora varie em alguma vertente, dependendo da sua teoria, tem bases no comportamento observável. Para os estudiosos comportamentalistas a aprendizagem são os acontecimentos ocorrido no organismo, sendo ele humano ou não, provindos do resultado de experiências vividas. Mudanças no comportamento são evidências que o aprendizagem ocorreu. Mas apesar desses apontamentos o comportamentalismo não esclarece efetivamente elementos mais complexos da aprendizagem.

Todas essas teorias muito contribuíram para algum setores em algum momento na sociedade, isso não se pode negar, mas quando se leva em consideração essas teorias e as confrontam com o modelo atual do processo de ensino-aprendizagem na EPT, percebe-se que essas teorias não se encaixam nos moldes justaposto de uma educação que tenta, ainda mesmo que em processamento, galgar para uma educação unilateral, integral e cultural, agregando para isso métodos ativos de ensino.

Se forem utilizados processos de ensino-aprendizagem levando-se em grande parte subsídios das teorias de Watson e Pavlov, molda-se com certeza, educandos numa perspectiva de adestramento, acomodação e reprodução.

O encaixe do ensino proposto atualmente é predisposição nas experiências internas e anteriores dos alunos, levando em consideração pontos cognitivos, sociais, culturais e afetivos, circunstâncias essas rompidas pelas teorias abordadas.

Essas observações justificam, em muitos pontos, a não agregação de elementos comportamentais para a construção do educando na EPT, logo, vai de desencontro aos princípios e políticas selecionadas para esse novo modelo de educação. Em parte, é necessário cautela quando pretendese apropriar-se de ferramentas que em momentos anteriores, não serviram e nem se efetivaram como molde para uma educação integral, mas sim técnica, pois, a repetição e adestramento, sempre nos remeterá a essa ideia. 
ARAÚJO, R. G. de; JUNIOR, E. P. e S.; OLIVEIRA, C. A. de; OLIVEIRA, F. F. de;(2019) A concepção behaviorista de Pavlov e Watson: implicações na educação profissional

\section{Referências}

ALMEIDA, Alana Peixoto de et al. COMPARAÇÃO ENTRE AS TEORIAS DA APRENDIZAGEM DE SKINNER E BANDURA. Cadernos de Graduação: Ciências Biológicas e da Saúde, Marceió, v. 3, n. 1, p.81-90, nov. 2013.

ARAÚJO, Felipe. B. F. Skinner e o Behaviorismo. Disponível em: <https://www.infoescola.com/psicologia/b-f-skinner-e-o-behaviorismo/>. Acesso em: 20 jul. 2019.

ARAÚJO, Ronaldo Marcos de Lima; FRIGOTTO, Gaudêncio. Práticas pedagógicas e ensino integrado. Revista Educação em Questão, v. 52, n. 38, p. 61-80, 2015.

ARAÚJO, Ronaldo Marcos Lima; RODRIGUES, do socorro, Doriedson. Referências sobre práticas formativas em educação profissional: o velho travestido de novo frente ao efetivamente novo. Boletim técnico do SENAC, v. 36, n. 2, p. 51-63, 2010

AZEVEDO, Tiago. Diferenças entre Psicologia Cognitiva e Psicologia Comportamental (Behaviorismo). 2016. Disponível em: <https://psicoativo.com/2016/09/diferencas-psicologiacognitiva-psicologia-comportamental-behaviorismo.html>. Acesso em: 20 jul. 2019.

BARATO, Jarbas Novelino. Conhecimento, Trabalho e Obra: uma proposta metodológica para a educação profissional. Boletim Técnico do Senac, v. 34, n. 3, p. 4-15, 2008.

BOGDAN, Robert C. et al. Investigação qualitativa em educação: uma introdução à teoria e aos métodos. 1994.

CASTAÑON, Gustavo Arja. O COGNITIVISMO E O DESAFIO DA PSICOLOGIA CIENTíFICA. 2006. 485 f. Tese (Doutorado) - Curso de Psicologia, Programa de Pós Graduação em Psicologia, Universidade Federal do Rio de Janeiro, Rio de Janeiro, 2006. Cap. 6.

COELHO, Marco Antônio; DUTRA, Lenise Ribeiro. Behaviorismo, cognitivismo e construtivismo: confronto entre teorias remotas com a teoria conectivista. Caderno de Educação, Pelotas, v. 1, n. 49, p.51-76, 2018.

GIL, Antônio C. Métodos e técnicas de pesquisa social. 5. ed. São Paulo: Atlas, 2006. KAHHALE, Edna Maria Peters et al. A diversidade da psicologia: uma construção teórica. 4. Ed. São Paulo: Cortez, 2011.

MATTAR, F. N.. Pesquisa de Marketing. Metodologia e Planejamento. 6 ed. São Paulo: Atlas, 2005. 
ARAÚJO, R. G. de; JUNIOR, E. P. e S.; OLIVEIRA, C. A. de; OLIVEIRA, F. F. de;(2019)

A concepção behaviorista de Pavlov e Watson: implicações na educação profissional

MOREIRA, Marcos Antônio. Teorias de Aprendizagem. São Paulo: Epu, 1999.

OLIVEIRA, Sílvio Luiz de. Metodologia científica aplicada ao direito. São Paulo: Pioneira Thomson Learning, 2002.

OSTERMANN, Fernanda; CAVALCANTI, Cláudio José de Holanda. Teorias de Aprendizagem. Porto Alegre: Evangraf; UFRGS, 2011. $51 \mathrm{p}$.

PAULA, Marcos Antonio Freire de Paula; MACHADO, Alexsandro dos Santos. EdUCAÇÃo PROFISSIONAL NO BRASIL: FORMAÇÃO PARA O TRABALHO OU PARA A CIDADANIA?. Seminário Gepráxis, Vitória da Conquista - Bahia - Brasil, v. 6, n. 6, p 3007-3027, 2017.

PROFISSIONAL NO BRASIL.2016. NO. 40, PP. 152-169. Disponível em: <http://www.eses.pt/interaccoes>. Acesso em: 27 abr. 2019.

RIES, Bruno Edgard. Condicionamento respondente: Pavlov. In: Jorge La Rosa. (Org.). Psicologia e Educação: Significado do aprender. Porto Alegre: EDIPUCRS, 2006.

SANTANA, Ana Lucia. BEHAVIORISMO. $2016 . \quad$ Disponível em: <https://www.infoescola.com/psicologia/behaviorismo/>. Acesso em: 20 jul. 2019.

SANTOS, José Alex Soares. Teorias da Aprendizagem: Comportamentalista, Cognitivista e Humanista. Disponível em: <http://www.alex.pro.br/teorias_aprend3.pdf>. Acesso em: 20 jul. 2019.

SCHULTZ, Duane P.; SCHULTZ, Sydney Ellen. História da psicologia moderna. 9. Ed. São Paulo: Cengage Learning 2012.

SERIO, Tereza Maria de Azevedo Pires. O behaviorismo radical e a psicologia como ciência. Rev. bras. ter. comport. cogn., São Paulo , v. 7, n. 2, p. 247-262, dez. 2005 . Disponível em <http://pepsic.bvsalud.org/scielo.php?script=sci_arttext\&pid=S1517-

$55452005000200009 \& \operatorname{lng}=$ pt\&nrm=iso>. acessos em 20 jul. 2019.

SOARES, Gabriel de O.. O Comportamentalismo de Pavlov, Watson e Skinner. 2013. Disponível em: <http://psicologiadaeducacao-portfolio.blogspot.com/2013/02/o-comportamentalismo-de-pavlovwatson-e.html>. Acesso em: 24 abr. 2019.

TERRA, Márcia. O BEHAVIORISMO EM DISCUSSÃO. 03/04/2019. Disponível em: <http://www.unicamp.br/iel/site/alunos/publicacoes/textos/b00008.htm>. Acesso em: $10 \mathrm{abr}$. 2019. 
ARAÚJO, R. G. de; JUNIOR, E. P. e S.; OLIVEIRA, C. A. de; OLIVEIRA, F. F. de;(2019). A concepção behaviorista de Pavlov e Watson: implicações na educação profissional

VIEIRA, Alboni Marisa Dudeque Pianovski; SOUZA JUNIOR, Antonio de. A EDUCAÇÃO PROFISSIONAL NO BRASIL. Rev. Interações, Paraná, vol. 12 n. ${ }^{\circ} 40$ (2016): Políticas Educacionais e Gestão da Escola.

VILELA, Ana Maria Jacó; FERREIRA, Arthur Arruda Leal; PORTUGAL, Francisco Teixeira (Ed.). História da psicologia: rumos e percursos. Nau Editora, 2007 